REVIEW ARTICLE

Received 5 Jul 2016 | Accepted 16 Nov 2016 | Published 20 Dec 2016

DOI: $10.1057 /$ palcomms.2016.94

\title{
Women in management: perspectives on a decade of research (2005-2015)
}

\author{
Paola Paoloni ${ }^{1}$ and Paola Demartini ${ }^{2}$
}

\begin{abstract}
Awareness of gender as a central feature in all aspects of everyday life and society has become more and more widespread. The dynamic and constantly evolving nature of the social sciences reflects the increasing concern for gender studies. This article provides a review of some of the recent literature (published in specialist journals) on gender in management and organizations to examine contributions from academics associated with different research areas. A total of 723 articles are examined from two key journals (Gender, Work \& Organisation [GWO] and Gender in Management [GIM]) to outline leading issues and themes in recent research over the period 2005-2015. While we identify several similarities between the two journals, 'Corporate Governance' is the topic that seems to capture most attention in GIM, while GWO's coverage is more focused on 'Discrimination' in the workplace, 'Differences between men and women' and 'Conflicts of interest'. This paper contributes to the literature in two ways. First, it provides a focused analysis of gender research published over a 10-year period. In addition, it outlines areas for future research in the field of gender in management and organization (that is, gender quotas, new business opportunities for female entrepreneurs) and advocates for a more interdisciplinary research approach. This article is published as part of a collection on the role of women in management and the workplace.
\end{abstract}

\footnotetext{
${ }^{1}$ Niccolò Cusano University, Rome, Italy ${ }^{2}$ University of Rome 3, Rome, Italy
} 


\section{Introduction}

esearch into gender in management and organizations is constantly evolving. When a research field is dynamic it can be beneficial to step back and take stock of emerging themes and patterns to both critique the current state of research and inform future research agendas. By understanding the dominant issues, we can build and develop new knowledge. Thus, the purpose of this article is to examine the evolving field of research in gender in management and organizations.

Initial research into gender in management and organizations stems from the 1970s, particularly by authors of Anglo American origin (Schrier, 1975). Previously the research field was neglected (De Carlo and Lyons, 1979) and the few existing studies were androcentric with theoretical reflection centred around the figure of manager or entrepreneur conceived as neutral, but described on the basis of features and attributes that are typically male (Schwartz, 1976).

Early studies then adopted a predominantly male vision in both explaining organizational behaviour and in identifying the explanatory variables of the choices and behaviours of entrepreneurs when starting and managing a business. Therefore, the view of women in the business world was oriented to the past. Women in management and organizations were not perceived as a manifestation of a natural social evolution, in which the woman is no longer constrained by the boundaries of her role as mother, wife, and/or housewife, but rather as an exception, of interest because the dominant interpretive model is masculine.

However, since the early 1980s there has been increased interest in women managers and entrepreneurs, often from an interdisciplinary perspective, combining, for instance fields such as sociology, psychology, management, and organizational studies and economics. This review seeks to evaluate the developing field of gender in management and organizations to identify dominant research topics and uncover those yet to be explored. It reviews recent literature in the field from different perspectives: corporate governance; female entrepreneurship (Paoloni, 2011; Paoloni and Dumay, 2015); conflicts of interest; differences between men and women; discrimination; other. We examined 723 articles from two key specialist journals published between 2005 and 2015 (Gender, Work \& Organisation [GWO] and Gender in Management [GIM]).

Adopting a structured literature review methodology (Massaro et al., 2016) we asked the following research questions:

- RQ1. What is the focus of the gender literature?

- RQ2. How is research on women in work and management developing in leading journals in the field?

In answering these questions this review contributes to the literature by analysing gender research published over the period 2005-2015, to gain a better understanding of the direction of contemporary women in work and management research. It highlights the emergence of women in corporate governance as a major area of research and draws attention to other key emerging research themes in the literature. It also identifies a growing focus on applied research and signs of a narrowing of the gap between gender research and practice.

\section{Methodology}

This article uses a structured literature review (SLR) method as proposed by Massaro et al. (2016). SLRs are becoming more commonplace as technology now allows researchers to easily gather large volumes of articles relevant to a particular research field. Thus, a SLR allows researchers to quickly analyse the attributes of a particular research field and develop insightful research questions and directions that are likely to differ from those of a traditional authorship literature review. While the value of traditional reviews "lies in the fact that they are written by someone with a detailed and well-grounded knowledge of the issue" (Petticrew and Roberts, 2008: 10), a SLR follows a specific methodology that selects and evaluates contributions, analyses and synthesizes data, and finally it reports the research evidence with transparency, comprehensiveness and reproducibility (Tranfield et al., 2003; Littell et al., 2008; Denyer and Tranfield, 2009). In this article, we adapt Massaro et al.'s (2016) method as outlined in the following sub-sections.

Selection of articles. We analyze the attributes of 723 articles on gender in management and organization published between 2005 and 2015 from two key journals: Gender Work \& Organization (GWO) and Gender in Management: An International Journal (GIM) as shown in Table 1. These are the leading journals in the field and we use a ten-year time period because it is short enough to ensure we are analyzing the most recent literature and long enough so we can uncover emerging research trends.

GWO provides "a forum for papers that go beyond a traditional oppositional-binary concept of gender", publishing international theoretical, epistemological and methodological papers that engage with sociological and/or gender theory. It invites contributions from all disciplinary perspectives, including anthropology, history, labour economics, law, philosophy, politics, psychology and sociology. Common keywords of these studies are: work, organization, industrial relations, anthropology, history, labour economics, law, philosophy, politics, psychology, sociology, management, recruitment, career, development, journal, analysis, research, periodical, article, employment and law (see http:// onlinelibrary.wiley.com/journal/10.1111/\%28ISSN\%291468-0432).

GIM specifically addresses the theme of female entrepreneurship and management. It focuses upon empirical research, theoretical developments, practice and current international issues in the field. It publishes research, conceptual and thought pieces from both researchers and practitioners within the global gender in management field (http://www.emeraldinsight.com/journal/gm).

Defining the analytical framework. The structured literature review is an iterative process in which the taxonomy of research themes and issues is developed and refined throughout the review and writing process. For this review, we first examined the framework developed by Guthrie et al. (2012: 71) and then deleted, added and or changed categories and their attributes according to which were most applicable to the research questions. Where

\begin{tabular}{|c|c|c|c|c|c|}
\hline \multicolumn{3}{|l|}{ GWO } & \multicolumn{3}{|c|}{ GIM } \\
\hline Year & Issues & Articles & Year & Issues & Articles \\
\hline 2005 & 6 & 27 & 2005 & 8 & 35 \\
\hline 2006 & 6 & 26 & 2006 & 8 & 38 \\
\hline 2007 & 6 & 28 & 2007 & 7 & 31 \\
\hline 2008 & 6 & 28 & 2008 & 8 & 36 \\
\hline 2009 & 6 & 30 & 2009 & 8 & 32 \\
\hline 2010 & 6 & 34 & 2010 & 8 & 41 \\
\hline 2011 & $6+1$ & 41 & 2011 & 8 & 33 \\
\hline 2012 & 6 & 34 & 2012 & 8 & 28 \\
\hline 2013 & 6 & 47 & 2013 & 8 & 23 \\
\hline 2014 & 6 & 36 & 2014 & 8 & 26 \\
\hline 2015 & 6 & 38 & 2015 & 8 & 31 \\
\hline Total & & 369 & Total & & 354 \\
\hline
\end{tabular}


uncertainty existed, we also consulted other academics for input. For example, we created the article type category named "other" to include all editorials, forewords, tributes, notes and comments. As we reviewed and classified articles and discovered new attributes we placed these into loose and emerging classifications. Thus, throughout the review process the classifications were refined and adapted. Table 2 presents the taxonomy of contemporary research categories and attributes that emerged from this process and make up the analytical framework.

We selected the final categories after reading the titles, abstracts and keywords of the articles. When we could not classify an article based on these attributes, one author searched and/or read the full article until it could be properly classified. Two authors worked together to spot-check classifications and coding for consistency. When there was ambiguity or uncertainty about a code, the authors discussed the coding until they agreed.

The purpose of the category "article focus" is to identify the specific focus of articles in order to gain insights into which topics are of continuing interest to scholars or otherwise. They are outlined below.

- A1 Corporate governance includes those articles about the presence of women on boards of directors, audit or other

\section{Table 2 | Analytical framework}

A. Article focus

A1-Corporate governance

A2-Female entrepreneurship

A3-Conflicts of interest

A4-Differences

A5-Discrimination

A6-Other

B. Research area

B1-Psychology

B2-Political and social

B3-Communication

B4-Engineering

B5-Business

B6-Non-academic

B7-Health

B8-Management

B9-Human Science

B10-Other

C. Geographical area

C1-Comparative

C2-Middle East

C3-South America

C4-North America

C5-North Europe

C6-South Europe

C7-Asia

C8-Africa

C9-UK

C10-Oceania

D. Research methods

D1-Literature review

D2-Qualitative

D3-Quantitative

D4-Mixed methods

D5-Normative

D6-Other company committees. A1 also includes articles concerned with career paths, the glass ceiling phenomenon or the pink share. ${ }^{1}$

- A2 Female entrepreneurship includes female entrepreneurship more broadly and specifically, the family business, relational capital, the formal and informal networks that women entrepreneurs activated during the life cycle of their company, and different problems that women have to overcome in doing business.

- A3 Conflicts of interest include articles about conflicts between work and family, maternity, work-life balance, career cycle/life cycle, and age and career paths.

- A4 Differences between men and women.

- A5 Discrimination at work includes discrimination against women in the workplace, and in the political, economic and social fields.

- A6 other collects all those articles that do not belong to other categories like niche research, the evolving situation of women, special issues, general review articles, the social situation of women in particular regions (Arab, Japan, Islamic).

The category "research area" is used to classify articles based on the field to which they belong. Many articles were interdisciplinary in nature. As many articles were from research centres, rather than university departments, we also incorporated this information to accurately understand the dominant perspective taken. We established the following categories:

- psychology;

- political, sociology sciences;

- communication, education, anthropology, human sciences, philosophy, geography;

- engineering and technology;

- business combined with other fields of research;

- management (general management, organization, marketing and so on);

- Non-academic (that is, centre studies);

- biomedical ethics, health and social care;

- arts and social, cultural, humanistic sciences:

- other (editorials, generic articles and so on).

In terms of geographical origin of the research, we classified the articles not based on the area of origin of the author, but the location of the research (for example, regardless of the author's location, if an article analysed the careers of women in Japan, it was categorized as Asian). The following categories were established:

- Comparative Study; Comparative study includes research comparing different country contexts. The UK is not included in Europe because there was a high number of UK-based studies, sufficient to form its own category.

- Middle East (Emirates, Israel);

- South America (Argentina, Dominican Republic);

- North America (Canada, the United States);

- Northern Europe (Austria, Belgium, Denmark, Switzerland, Netherland, Ireland, Finland, France, Netherland, Ireland, Finland, France, Germany, Iceland, Norway, Sweden, Poland);

- Southern Europe (Greece, Turkey, Spain, Portugal, Italy);

- Asia China Japan, Korea, Singapore, Sri Lanka);

- Africa;

- The United Kingdom;

- Oceania.

The articles were also categorized according to research method. The category "Other" includes those articles in special issues or critiquing other articles or responding to critiques. 
We established the following methods, including whether the work is qualitative, quantitative or mixed.

- literature analysis;

- qualitative research;

- quantitative research;

- mixed methods research (which includes both qualitative and quantitative methodology);

- discussion, conceptual or critical article (no empirical data or specific analysis of the literature);

- other (editorials, generic article where the methodology is not specified, or critical articles).

\section{Results}

This section provides the descriptive results of the study and offers a discussion about the results to answer research questions 1 and 2: How is research inquiring into gender developing? What is the focus of the gender literature? We do this by summarising the broad trends in gender research over the last 10 years by offering a comparison between the two journals.

Article focus. For the journal GIM, corporate governance is the main focus of research over the period (97 of 354 articles), followed by an analysis of differences between men and women (77) and conflict of interests (63). (Figs. 1 and 2)

For $G W O$, consistent with its interdisciplinary approach, the main focus of researchers is: discrimination and differences between men and women are first with 100 of 369 articles, followed by other (76) and conflicts of interest (67).

Research area. For both journals, the main area of research of the authors is management. Future research could break down for

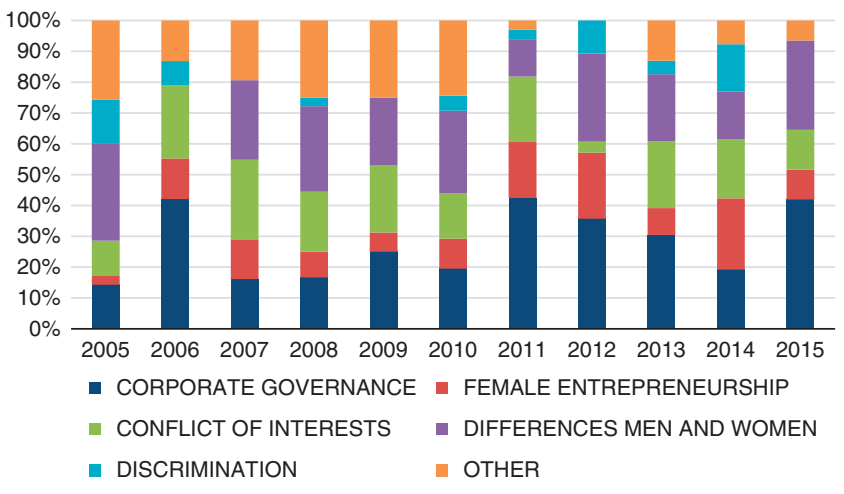

Figure 1 | GIM-article focus

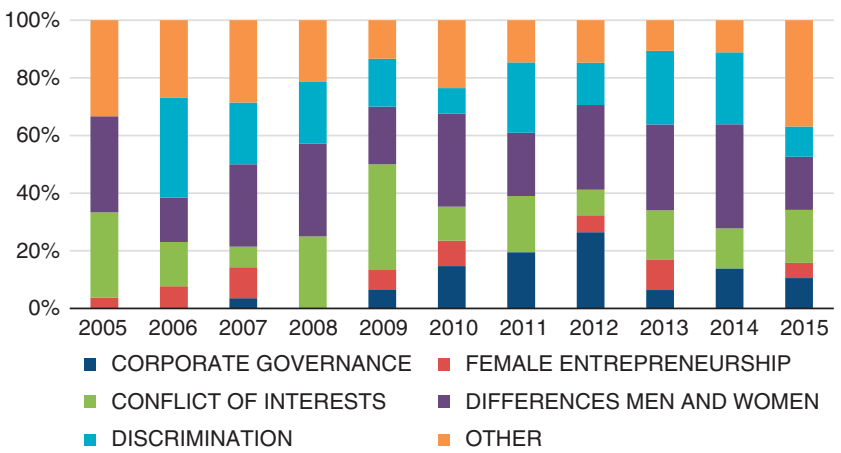

Figure 2 | GWO-article focus deeper analysis to establish more specificity (that is, accounting, marketing, finance) or theoretical frameworks the articles have adopted. For GIM the other two areas that dominate are psychology and political and social studies. (Figs. 3 and 4)

Geographical area. For both journals, the geographical focus of articles was the United Kingdom and North America. North Europe was the next most common location, with articles about women in Oceania, South Europe, Arab States and Asia less common and those focusing on South America and Africa very rare. This is not surprising because there is a long tradition of gender studies in the United Kingdom and North America. However, it may be interesting to understand why in other countries such as South Europe and Asia there has been less interest. One possible explanation is the language barrier, with perhaps more literature in the native languages of these locations. (Figs. 5 and 6)

Research method. Almost half of the articles published in GIM journal adopt a qualitative research approach (176) but this trend has been decreasing over the last 5 years. Worth noting, is the number of articles (23) undertaking a literature review. Articles using a quantitative research method have been also published frequently in the last decade (116 of 354). In GWO, most authors present qualitative articles (253 of 369). In both journals, a normative approach is not common (on average $10 \%$ of the total amount of articles) and mixed methods are seldom used. (Figs. 7 and 8)

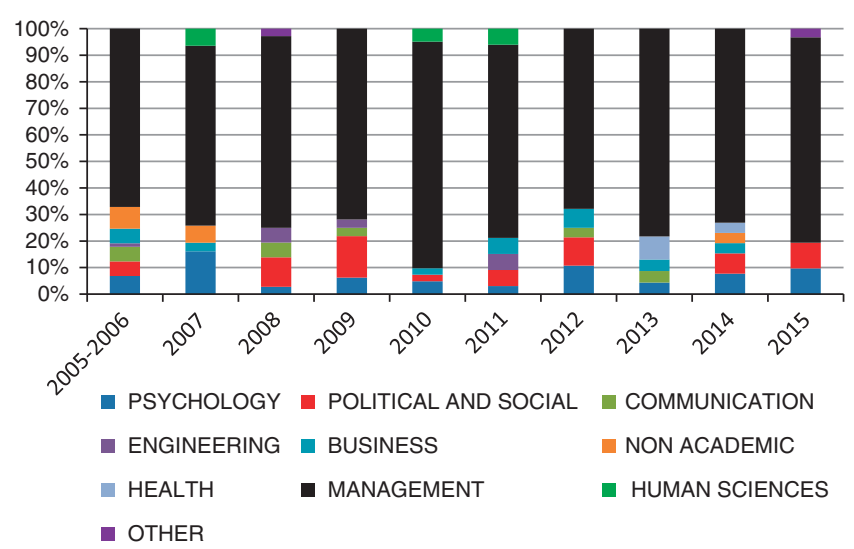

Figure 3 | GIM-research areas

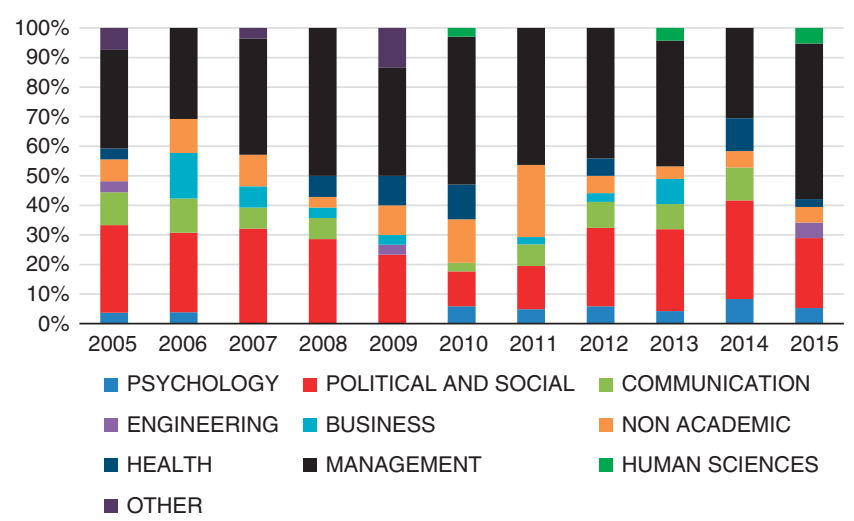

Figure 4 | GWO-research areas 


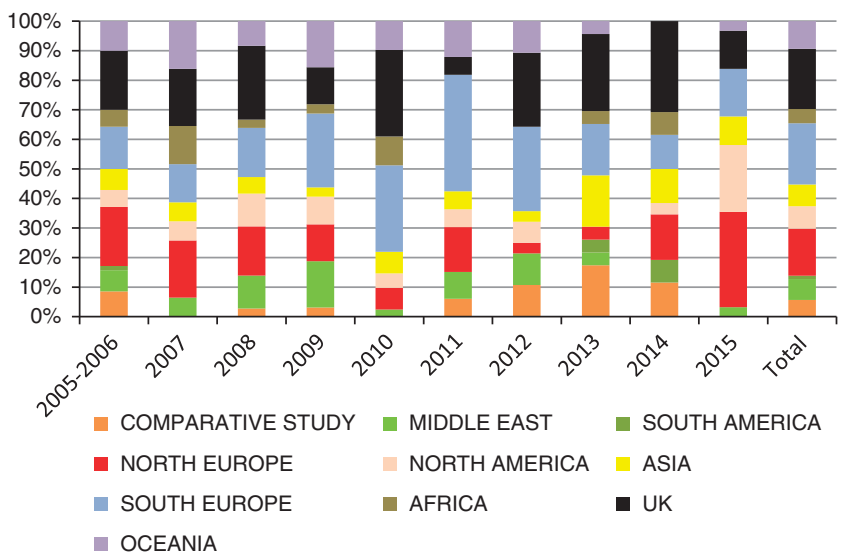

Figure 5 | GIM-geographical areas

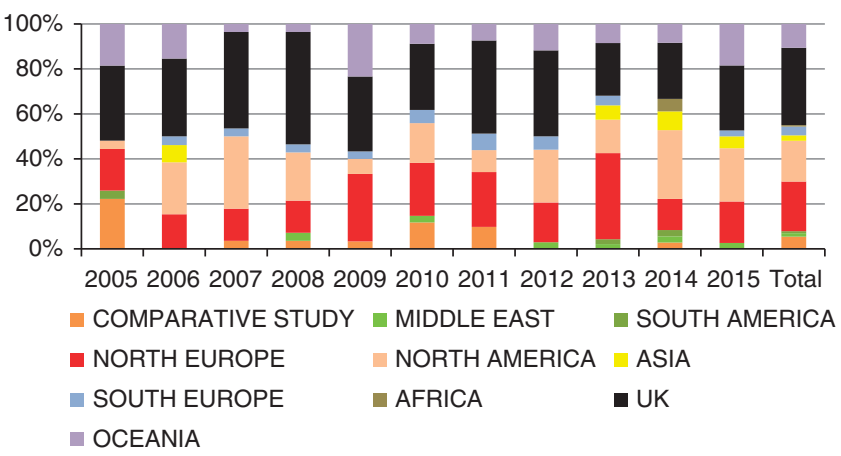

Figure 6 | GWO-geographical areas

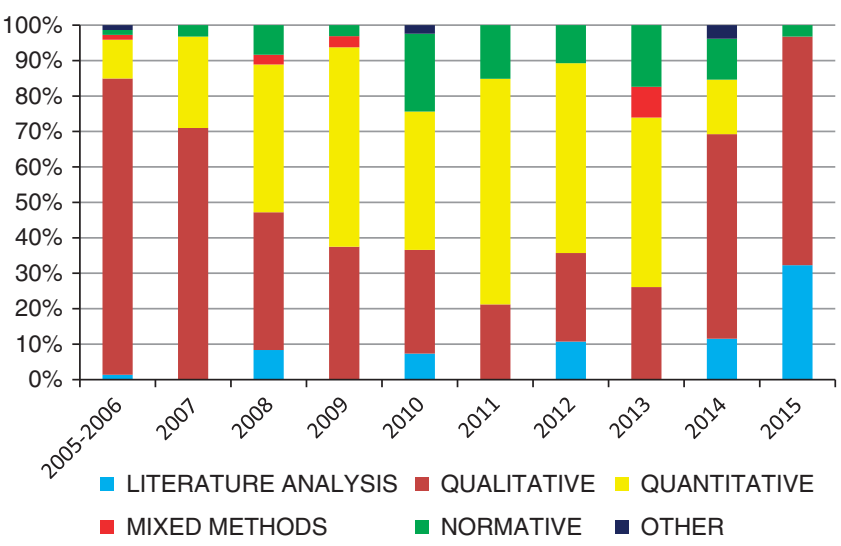

Figure 7 | GIM-research methods

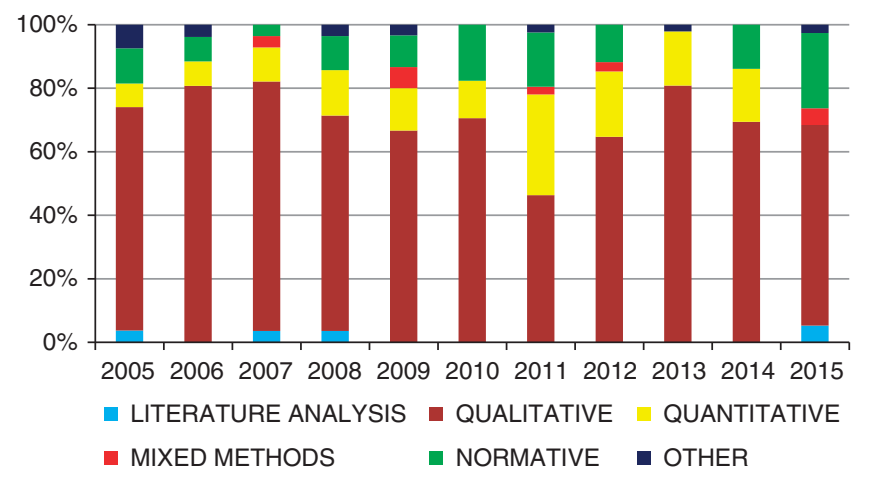

Figure 8 | GWO-research methods

\section{A research agenda}

This section provides the descriptive results of the study to answer RQ1. What is the focus of the gender literature? and RQ2. How is research on women in work and management developing in leading journals in the field?

Here a summary of the broad trends in gender research over the last 10 years and a comparison between the two journal, is presented. To do this, we examined whether and how in the past 10 years have changed the origin of the article, the methodology used and the department of origin of the two journals.

The main conclusions are the following:

In both journals, we find several similarities:

- As far as focus is concerned, women and corporate governance is the topic that seems to capture more attention.

- Most authors belong to the Management field of research. It follows researchers involved in political and social science disciplines

- Most research has been developed focusing on gender issues in Anglo-Saxons countries such as the United Kingdom and North America

- The method most frequently used in both Journal is the qualitative one. However, in GIM Journal, a remarkable number of articles (almost 36\%) show a quantitative approach.

We find that research on gender is multifaceted. Scholars involved in gender enquiry belong to many fields of research. Even within each discipline, researchers address the subject of gender through different lenses, applying a range of theoretical frameworks and methods. Consequently, we see that research on gender crosses the boundaries of different areas of study and we anticipate further interdisciplinary investigations and cross-fertilization.

The dominance of academics from an Anglo-American background, suggests a "Northern perspective", with few contributions from Southern Europe, South America and Africa. We see that the future may incorporate more studies from these areas to close this gap and as evidence we point to a research network on gender studies called "IPAZIA" in which we are involved, that brings together Italian and Mediterranean countries to promote investigation on women in work and management.

Given that we are living in a time of tremendous change (as regards technology, economy, culture and society), with rapid innovation, globalization, growth of economies and lengthening life expectancy we anticipate these interrelated phenomena, which impact on every aspect of life, increasingly to be the subject of gender studies. These impacts may also lead to uncertainties and contradictions that can in turn threaten and disrupt or bring opportunities and benefits. Future research may seek to reconcile these contradictions. Globalization is combined with localism; diversity is seen as a driver for creating value in organizations; migrants' integration can be considered a lever to regenerate the stagnant economies of the advanced countries; sustainability in the medium to long term is a main goal for businesses seeking to combine profitability with attention to the environment and social welfare. Gender research can provide a perspective on the intersection of these fields of research as they relate to sex, social and cultural identity, economics, society, institutions, and geopolitical contexts (Martin, 2006).

In more specific terms, given the relevance of corporate governance as a research field (Grisoni and Beeby, 2007; Guillaume and Pochic, 2009; Healy et al. 2011; Tlaiss and Kauser, 2011), we expect to see further exploration of this, in particular, in relation to quotas and their impact on corporate performance and on the emotions and perceptions of men.

In the field of female entrepreneurship (Jamali, 2009; Kirkwood, 2009), articles with a higher number of references have examined 
particular geographical contexts, industrial sectors, or different psychological features that distinguish women from men entrepreneurs (Tyler and Cohen; 2008; Lewis and Simpson, 2010). However, we found a lack of investigation as regard to new businesses opportunities in the sectors of the green economy, big data management and social media, which gives opportunities for future research. Another relevant topic, which we expect to gain momentum, concerns women entrepreneurs and business network (Brunetto and Farr-Wharton, 2007; Klyver and Terjesen, 2007; Singh and Belwal, 2008; Demartini and Paoloni, 2012).

The stream of research concerning differences between women and men includes studies addressing diversity and equality within varying socio-demographic backgrounds and geo-political contexts (Martin, 2006; Holvino, 2008), as well as in academic careers (Probert, 2005) and other professions (Powell et al. 2009). In the light of the new challenges of the fourth industrial revolution (Schwab, 2016), we suggest that more research is needed in this field to bridge the gender gap in science, technology, engineering and mathematics (Friedman, 1989). This research could be successful to promote scientific and technical training for girls and raise the debate on new digital skills needed to enter the world of work (Cooper, 2006).

Most research of conflict of interests concerns balancing time between work and family (McDonald et al., 2005; Smithson and Stokoe, 2005; Wood and Newton, 2006; Ezzedeen and Ritchey, 2009). Other authors focus more on discrimination against women in the workplace and in other political, economic and social contexts (for example, Eriksson-Zetterquist and Styhre, 2008; Bird, 2011; Nentwich and Kelan, 2014).

For future research in these two fields, we deem that in order to suggest possible and applicable solutions to bridge the gender gap, an interdisciplinary approach that combines management and organization, psychology, sociology, political economic and law, may be applicable.

\section{Conclusion}

This article contributes to the literature in several ways. First, it provides a focused analysis of gender research published over ten years, allowing researchers to gain a better understanding of the direction of the contemporary gender research field. Second, it draws attention to key emerging research themes in the literature. Finally, it suggests a growing focus on applied research and signs of a narrowing of the gap between gender research and practice.

The future research directions discussed above are about opening up new fields of enquiry, addressing neglected issues and consolidating the traditional fields of gender literature. We must challenge the status quo, employ innovative methodologies, provide empirical studies on gender, suggest applicable solutions to bridge the gender gap and help develop broader theoretical research.

Our conclusions should be considered after taking into account the following limitations. First, the selection of journals was restricted to two specialist journals. Results could vary if more journals were included and if other forms of scholarly activities were included (for example, monographs, conference articles, books, book chapters, $\mathrm{PhD}$ theses and so on). Second, although the coding process was performed systematically, there could be errors of omission and coding as a result of coder bias. Third, the addition of "other" in classifications may have hidden some interesting findings.

\section{Note}

1 Pink share refers to rules aimed at protecting gender equality within representative bodies.

\section{References}

Bird SR (2011) Unsettling Universities' Incongruous, Gendered Bureaucratic Structures: A Case-study Approach. Gender, Work \& Organization; 18 (2): 202-230.

Brunetto Y and Farr-Wharton R (2007) The moderating role of trust in SME owner/managers' decision-making about collaboration. Journal of Small Business Management; 45 (3): 362-387.

Cooper J (2006) The digital divide: The special case of gender. Journal of Computer Assisted Learning; 22 (5): 320-334.

De Carlo J and Lyons PR (1979) A comparison of selected personal characteristics of minority and non-minority female entrepreneurs. Journal of Business Management; 1979 (1).

Demartini P and Paoloni P (2012) The relational capital in female SMEs. Journal of Academy of Business and Economics; 12, 23-32.

Denyer D and Tranfield D (2009) Producing a systematic review. In Buchanan DA and Bryman A (eds). The Sage Handbook of Organizational Research Methods. Sage Publications: Thousand Oaks, CA, pp 671-689.

Eriksson-Zetterquist $U$ and Styhre A (2008) Overcoming the glass barriers: Reflection and action in the "women to the top" programme. Gender, Work \& Organization; 15 (2): 133-160.

Ezzedeen SR and Ritchey KG (2009) Career advancement and family balance strategies of executive women. Gender in Management: An International Journal; 24 (6): 388-411.

Friedman L (1989) Mathematics and the gender gap: A met-analysis of recent studies on sex differences in mathematical tasks. Review of Educational research; 59 (2): 185-213.

Guthrie J, Ricceri F and Dumay J (2012) Reflections and projections: A decade of intellectual capital accounting research. British Accounting Review; 44 (2): 68-92.

Grisoni L and Beeby M (2007) Leadership, gender and sense-making. Gender, Work and Organization; 14 (3): 191-209.

Guillaume C and Pochic S (2009) What would you sacrifice? Access to top management and the work-life balance. Gender, Work \& Organization; 16 (1): 14-36.

Healy G, Bradley H and Forson C (2011) Intersectional sensibilities in analysing inequality regimes in public sector organizations. Gender, Work \& Organization; 18 (5): 467-487.

Holvino E (2008) Intersections: The Simultaneity of Race, Gender and Class in Organization Studies. Gender, Work \& Organization; 17 (3): 248-277.

Jamali D (2009) Constraints and opportunities facing women entrepreneurs in developing countries. Gender in Management: An International Journal; 24 (4): 232-251.

Kirkwood J (2009) Motivational factors in a push-pull theory of entrepreneurship. Gender in Management: An International Journal; 24 (5): 346-364.

Klyver K and Terjesen S (2007) Entrepreneurial network composition: An analysis across venture development stage and gender. Women in Management Review; 22 (8): 682-688.

Lewis P and Simpson R (2010) Meritocracy, difference and choice: Women's experiences of advantage and disadvantage at work. Gender in Management: An International Journal; 25 (3): 165-169.

Littell JH, Corcoran J and Pillai V (2008) Systematic Reviews and Meta-Analysis. Oxford University Press.

Martin PY (2006) Practising gender at work: Further thoughts on reflexivity. Gender, Work \& Organization; 13 (3): 254-276.

Massaro M, Dumay J and Guthrie J (2016) On the shoulders of giants: Undertaking a "Structured Literature Review". Accounting, Auditing \& Accountability Journal; 29 (5).

McDonald P, Brown K and Bradley L (2005) Explanations for the provisionutilisation gap in work-life policy. Women In Management Review; 20 (1): 37-55.

Nentwich JC and Kelan EK (2014) Towards a topology of "doing gender": An analysis of empirical research and its challenges. Gender, Work \& Organization; 21 (2): 121-134.

Paoloni P (2011) La Dimensione Relazionale delle Imprese Femminili (trans. The Relational Dimension of Female Firm). Franco Angeli: Milan, Italy.

Paoloni P and Dumay J (2015) The relational capital of micro-enterprises run by women: the start-up phase. Gender in Management: An International Journal; 15 (2): 172-197.

Petticrew M and Roberts H (2008) Systematic Reviews in the Social Sciences: A Practical Guide. Wiley-Blackwell: Oxford, UK, p 354.

Powell A, Bagilhole B and Dainty A (2009) How women engineers do and undo gender: Consequences for gender equality. Gender, Work \& Organization; 16 (4): 411-428.

Probert B (2005) "I just couldn't fit it in": Gender and unequal outcomes in academic careers. Gender, Work \& Organization; 12 (1): 50-72.

Schrier JW (1975) The Female Entrepreneur. A Pilot Study. The centre for Venturing management.

Schwab K (2016) The Fourth Industrial Revolution. World Economic Forum: Geneva, Switzerland. 
Schwartz EB (1976) Entrepreneurship: A new female frontier. Journal of Contemporary business; winter: 47-76.

Singh G and Belwal R (2008) Entrepreneurship and SMEs in Ethiopia. Gender in Management: An International Journal; 23 (2): 120-136.

Smithson J and Stokoe EH (2005) Discourses of work-life balance: Negotiating "genderblind" terms in organizations. Gender, Work \& Organization; 12 (2): 147-168.

Tlaiss H and Kauser S (2011) The impact of gender, family, and work on the career advancement of Lebanese women managers. Gender in Management: An International Journal; 26 (1): 8-36.

Tyler M and Cohen L (2008) Management in/as comic relief: Queer theory and gender performativity in the office. Gender, Work \& Organization; 15 (2): 113-132.

Tranfield D, Denyer D and Smart P (2003) Towards a methodology for developing evidence-informed management knowledge by means of systematic review. British Journal of Management; 14 (3): 207-222.

Wood GJ and Newton J (2006) Childlessness and women managers: "Choice", context and discourses. Gender, Work and Organization; 13 (4): 338-358.

\section{Data availability}

The datasets generated and analysed in this study are not publicly available but are available from the corresponding author upon reasonable request.

\section{Additional information}

Competing interests: The Authors declare no competing financial interests.

Reprints and permission information is available at http://www.palgrave-journals.com/ pal/authors/rights_and_permissions.html

How to cite this article: Paoloni P and Demartini P (2016) Women in management: perspectives on a decade of research (2005-2015). Palgrave Communications. 2:16094 doi: $10.1057 /$ palcomms.2016.94.

(c) (i) This work is licensed under a Creative Commons Attribution 4.0 article are included in the article's Creative Commons license, unless indicated otherwise in the credit line; if the material is not included under the Creative Commons license, users will need to obtain permission from the license holder to reproduce the material. To view a copy of this license, visit http://creativecommons.org/licenses/by/4.0/ 